\title{
Presencia de bacterias en prótesis dentales durante el proceso de elaboración.
}

\author{
Presence of bacteria in dental prostheses during the elaboration process. \\ Mónica Badillo Barba,* Jorge Morales García,*,‡ María de los Ángeles Martínez Cárdenas,* \\ Amayrani Carachure Alejo, ${ }^{\S}$ María Guadalupe Chávez García,§ Vanessa García Ruíz ${ }^{\S}$
}

\section{RESUMEN}

Existe una creciente preocupación sobre el tema de la infección cruzada en clínicas y laboratorios dentales. El laboratorio odontológico debe seguir normas de bioseguridad que garanticen a todo el equipo de salud la prevención de estas infecciones. Los técnicos que allí laboran corren el riesgo de exponer su cara a salpicaduras, así como a rocíos de sangre y saliva. Este estudio fue diseñado para saber si los laboratorios a los que recurrimos cumplen con estas normas de bioseguridad, y qué tan confiados podemos estar de la desinfección por parte de ellos, ya que las prótesis deberían estar desinfectadas correctamente antes de colocarlas en boca.

Palabras clave: Prótesis, bacterias, desinfección.

\section{ABSTRACT}

There is growing concern about the issue of cross infection in dental clinics and laboratories. The dental laboratory must follow biosafety standards that guarantee the prevention of these infections to the entire health team. The technicians who work there run the risk of exposing their face to splashes and spray of blood and saliva. This study was designed to find out if the laboratories we use comply with these biosafety standards, and how confident we can be of their disinfection by them, since the prostheses should be properly disinfected before placing them in the mouth.

Keywords: Prosthesis, bacteria, disinfection.

\section{INTRODUCCIÓN}

L as prótesis dentales son instrumentos o aparatos confeccionados por los técnicos dentales en el laboratorio dental, pero diseñadas por el odontólogo, cuya misión es la de suplir las piezas dentarias pérdidas para reestablecer la función masticatoria y estética. ${ }^{1}$

Los laboratorios de prótesis dentales son establecimientos destinados al diseño, preparación, elaboración, fabricación, modificación y reparación de prótesis denta- les y aparatología, mediante la utilización de materiales, técnicas y procedimientos adecuados. Los laboratorios deberán disponer de los requisitos adecuados en función del tipo de prótesis dental que fabriquen. ${ }^{2}$

El riesgo de contaminación cruzada en clínicas dentales, así como la transmisión de microorganismos en laboratorios de prótesis se ha informado en varios estudios. Sofou y colaboradores han reportado que más de $60 \%$ de los trabajos recibidos en el laboratorio han estado contaminados. ${ }^{3}$

\footnotetext{
* Profesor Investigador, Departamento de Atención a la Salud de la Universidad Autónoma Metropolitana-Xochimilco. Ciudad de México, México.

‡ Profesor invitado de la UNITEC y Universidad Intercontinental. Ciudad de México, México.

§ Alumno de la Universidad Autónoma Metropolitana-Xochimilco. Ciudad de México, México.

Recibido: 26 de marzo de 2020. Aceptado: 26 de enero de 2021.
}

Citar como: Badillo BM, Morales GJ, Martínez CMÁ, Carachure AA, Chávez GMG, García RV. Presencia de bacterias en prótesis dentales durante el proceso de elaboración. Rev ADM. 2021; 78 (1): 13-21. https://dx.doi.org/10.35366/98382 
Esto constituye una amenaza para la seguridad de los técnicos dentales, quienes pueden adquirir microorganismos patógenos a partir de impresiones y otros artículos contaminados. Por otro lado, puede ocurrir una infección cruzada entre el personal dental y los pacientes por artículos contaminados enviados desde los laboratorios dentales a clínicas dentales. ${ }^{4}$

\section{Control de infecciones en el laboratorio de prótesis dental}

El control de infecciones en los laboratorios dentales fue recomendado por primera vez por la Asociación Dental Americana (ADA), a través de sus recomendaciones y pautas de los Centros para el Control de Enfermedades (CDC). ${ }^{5,6}$

La Administración de Salud y Seguridad Ocupacional de los Estados Unidos de América (OSHA) ha clasificado en tres categorías las labores efectuadas en los consultorios y laboratorios odontológicos, y cita que los procedimientos comprendidos en el control de infecciones también varían de acuerdo con esta clasificación. $^{7}$

- Categoría I: labores que comprenden exposición a sangre, saliva, otros líquidos y tejidos corporales. En esta categoría de trabajo, se debe exigir al trabajador usar todas las medidas protectoras convenientes.

- Categoría II: labores que no comprendan exposición a sangre, saliva u otros líquidos y tejidos corporales, aunque el empleo pudiera requerir el desempeño de labores categoría I no planeadas.

- Categoría III: labores que no comprenden la exposición ante sangre, saliva u otros líquidos corporales. A las personas que ejecutan este tipo de labores, no se les solicita que efectúen o ayuden en el área de trabajo del laboratorio.

El personal de las categorías I y II debe usar guantes, protección ocular, tapabocas (convenientemente contra el polvo y el rocío) y uniforme.

El empleado que realiza actividades categoría III sólo necesita tomar precauciones sistemáticas, la protección ocular y los tapabocas son indispensables al realizar labores vinculadas con riesgos. Es necesario limpiar a diario las superficies trabajo.?

\section{Desinfección de materiales y aparatología para laboratorio dental ${ }^{8}$}

Vázquez, en su estudio de control de la infección cruzada en los laboratorios de prótesis dental de Galicia, menciona los métodos de desinfección dependiendo de los materiales dentales utilizados (Tablas 1 y 2).

\section{Consultorio dental}

Cuando los aparatos protésicos metálicos Ileguen al consultorio procedente del laboratorio, deberán ser desinfectados siguiendo las mismas pautas que se utilizan para el instrumental operatorio; en caso de que ya se encuentren con acrílicos, se deberán desinfectar antes de ser introducidos en la boca del paciente. ${ }^{9}$

Las sustancias pulidoras del tipo de la piedra pómez, cuando son usadas sobre prótesis contaminadas, se convierten en un reservorio bacteriano y pueden permanecer contaminadas durante tres meses. Para prevenir infecciones es posible añadir a la piedra pómez un líquido desinfectante (cinco partes de hipoclorito de sodio por 100 partes de agua destilada). ${ }^{9}$

Tabla 1: Desinfección en materiales de impresión.

\begin{tabular}{lccc} 
& \multicolumn{3}{c}{ Solución desinfectante/Tiempo de exposición } \\
\cline { 2 - 4 } Material de impresión & Hipoclorito (1\%) & Iodóforos & Glutaraldehído (2\%) \\
\hline Alginato & $\mathrm{R} / 1 \mathrm{~min}$ & $\mathrm{R} / 1 \mathrm{~min}$ & $\mathrm{NR}$ \\
Silicona o mercaptano & $\mathrm{R} / 10 \mathrm{~min}$ & $\mathrm{R} / 10 \mathrm{~min}$ & $\mathrm{R} / 10 \mathrm{~min}$ \\
Polisulfuro de caucho & $\mathrm{R}$ & $\mathrm{NR}$ & $\mathrm{R} / 30$ min \\
Pasta zinquenólica & $\mathrm{NR}$ & $\mathrm{NR}$ & $\mathrm{R} / 30 \mathrm{~min}$ \\
Modelina & $\mathrm{NR}$ & & \\
\hline
\end{tabular}

$\mathrm{R}$ = recomendable; $\mathrm{NR}$ = no recomendable. 
Tabla 2: Soluciones desinfectantes en prótesis dentales.

\begin{tabular}{lccc} 
& & Desinfectante & \\
\cline { 2 - 3 } Aparato prótesis/ortodoncia & Hipoclorito (1\%) & Iodóforos & Glutaraldehído (2\%) \\
\hline Prótesis fijas & & & \\
Metal/porcelana & $\mathrm{R} / \mathrm{D}$ & $\mathrm{R} / \mathrm{D}$ & $\mathrm{R}$ \\
Metal/acrílico & $\mathrm{R} / \mathrm{D}$ & $\mathrm{R} / \mathrm{D}$ & $\mathrm{R}$ \\
Porcelana & $\mathrm{R} / \mathrm{D}$ & $\mathrm{R} / \mathrm{D}$ & $\mathrm{NR}$ \\
Acrílico & $\mathrm{R}$ & $\mathrm{R}$ & $\mathrm{NR}$ \\
Prótesis removible & $\mathrm{R} / \mathrm{D}$ & $\mathrm{NR}$ \\
Metal/acrílico & $\mathrm{R} / \mathrm{D}$ & $\mathrm{NR}$ \\
Acrílico/porcelana & $\mathrm{R}$ & $\mathrm{R} / \mathrm{D}$ & $\mathrm{NR}$ \\
Acrílico & $\mathrm{R} / \mathrm{D}$ & $\mathrm{R} / \mathrm{D}$ & $\mathrm{NR}$ \\
Ortodoncia & & $\mathrm{R}$ & $\mathrm{R}$ \\
Acrílico/alambres & $\mathrm{R}$ & $\mathrm{R}$ & $\mathrm{R}$ \\
Férulas de relajamiento & $\mathrm{R}$ & \\
Acrílico & Rociado o inmersión & $\mathrm{R}$ & \\
Modelos de yeso & & & \\
Rodetes de mordida & Rociado o inmersión & &
\end{tabular}

\section{Norma Oficial Mexicana NOM-045-SSA2-2005}

Dentro de esta rama existe una Norma Oficial Mexicana para la vigilancia epidemiológica, prevención y control de las infecciones nosocomiales (NOM-045-SSA2-2005), entiéndase como infección nosocomial a una infección contraída durante una estancia en un centro de salud. Esta Norma Oficial es de observancia obligatoria en todas las instituciones de atención, considerando los subcomponentes de información, supervisión, evaluación, coordinación, capacitación en Servicio e Investigación, como base para su funcionamiento operativo adecuado dentro del sistema de vigilancia epidemiológica de las infecciones nosocomiales, con el principio de evitar completamente que los pacientes pasen por una infección nosocomial, así como los factores a éstos; en caso de contraerla, nos explica los pasos a seguir con respecto a lo que se debe realizar y las consecuencias que trae consigo. ${ }^{10}$

Objetivo. Identificar la presencia de bacterias en prótesis entregadas por los laboratorios dentales.

\section{MATERIAL Y MÉTODOS}

Es un estudio microbiológico experimental, comparativo, observacional y de corte transversal. Se analizaron 20 prótesis entregadas por laboratorios dentales. Previo al
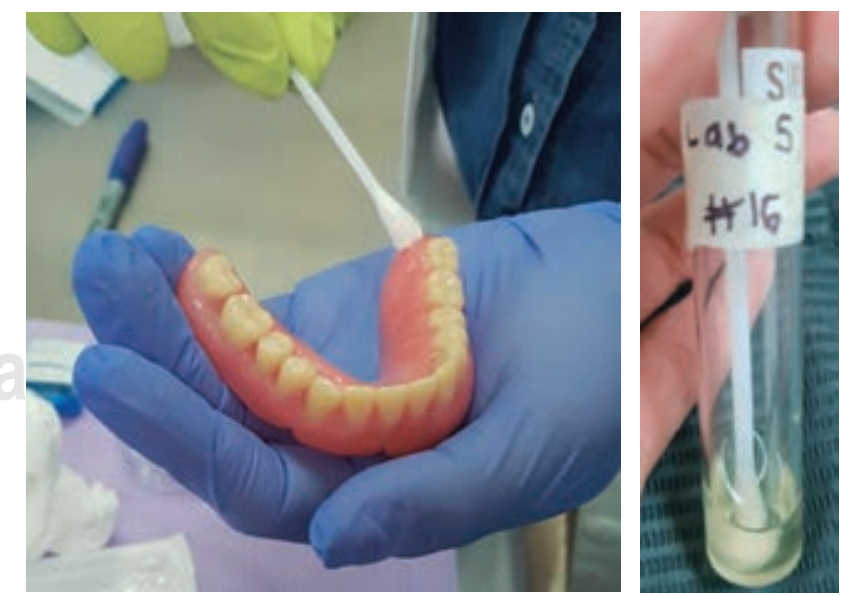

Figura 1: Toma de muestras de las piezas de alta. 

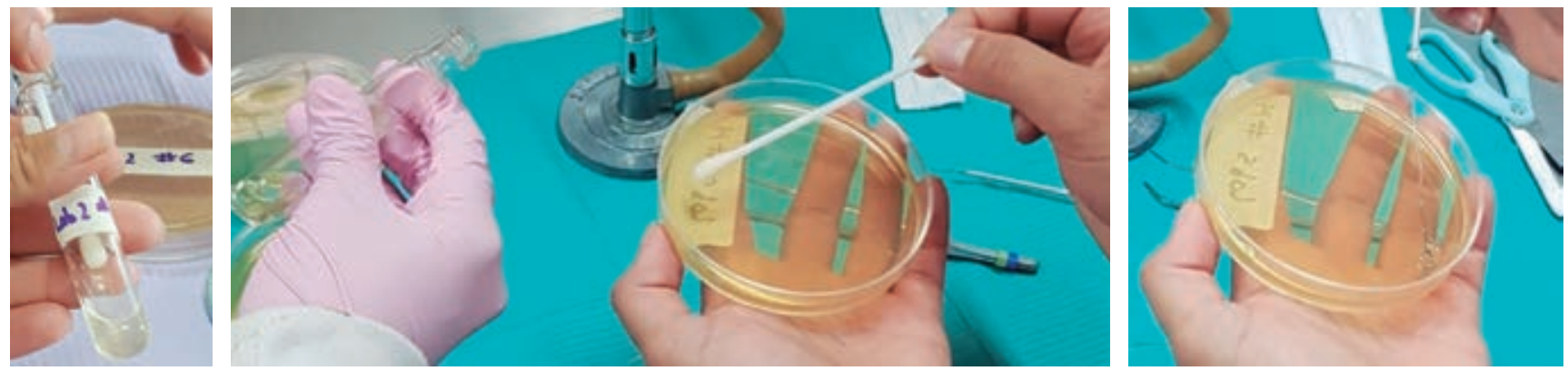

Figura 2: Cultivo en el agar cerebro corazón.
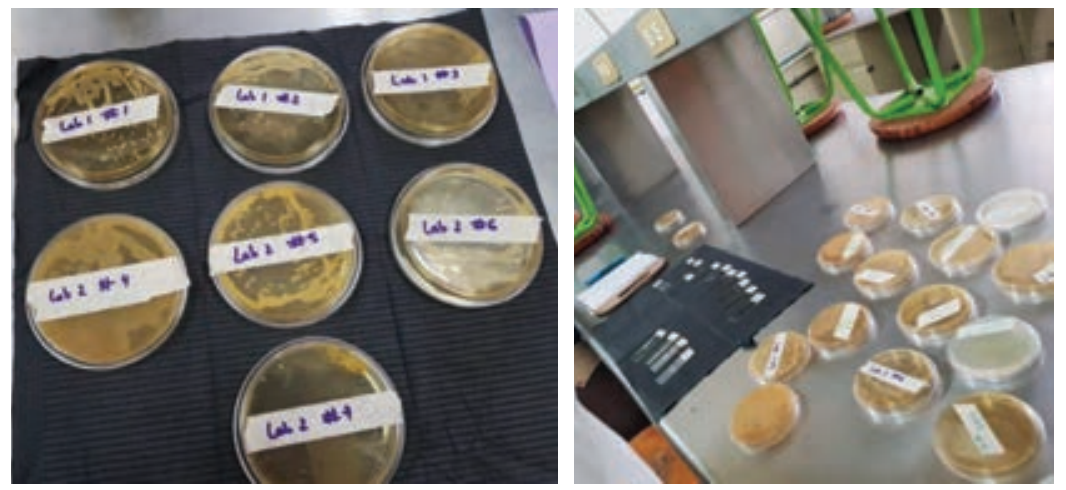

\section{Figura 3:}

Crecimiento bacteriano.

Figura 4:

Tinción de Gram.
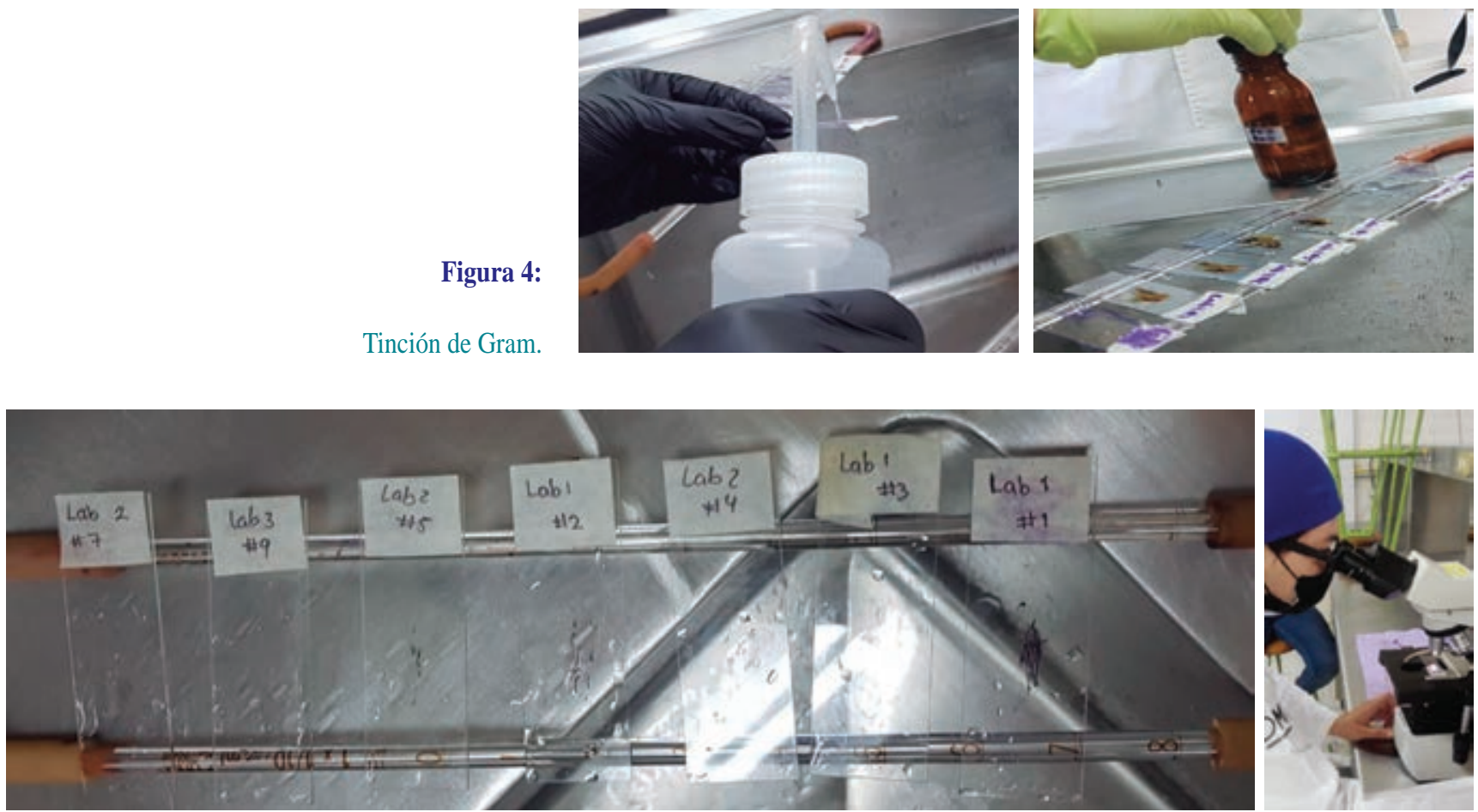

Figura 5: Visualización en microscopio. 


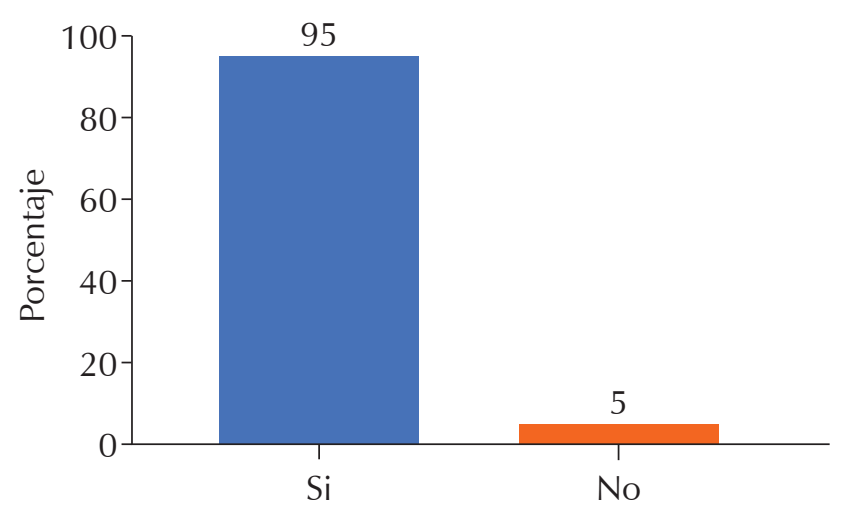

Figura 6: Presencia de bacterias.

\begin{tabular}{lrr}
\multicolumn{3}{c}{ Tabla 3: Tinción Gram. } \\
& $\mathrm{n}$ & $\%$ \\
\hline Gram positivo & 6 & 30.0 \\
Gram negativo & 7 & 35.0 \\
Gram positivo y negativo & 6 & 30.0 \\
Sin crecimiento & 1 & 5.0 \\
Total & 20 & 100.0 \\
\hline
\end{tabular}

estudio, se efectuó una estandarización, en la cual se obtuvo una kappa de 0.82. La base de datos se realizó en el programa SPSS versión 24, con lo que se llevó a cabo el análisis descriptivo para determinar medidas de tendencia central y de dispersión mediante la prueba estadística de ANOVA $p<0.05$.

Procedimiento. Se eligieron 20 prótesis clasificadas de la siguiente manera:

1. Prótesis metal-porcelana (2)

2. Prótesis metal (5)

3. Parcial removible (1)

4. Prótesis libres de metal (4)

5. Prótesis totales (8)

El estudio se realizó en tres fases:

1. Aislamiento bacteriológico de muestras. Para realizar el análisis bacteriológico, se tomaron muestras de cada una de las prótesis con hisopos estériles y solución salina, se introdujeron en tubos que contenían caldo de cultivo nutritivo de soya, previamente codificados.
Dichas pruebas se almacenaron a temperatura de 37 ${ }^{\circ} \mathrm{C}$ por 24 horas (Figura 1).

2. Cultivo bacteriológico en el agar. Infusión cerebro corazón. Se realizó el cultivo de las muestras obtenidas de los tubos de caldo soya en las cajas de Petri codificadas y con el agar infusión cerebro corazón. Las cajas se almacenaron a una temperatura de 37 ${ }^{\circ} \mathrm{C}$ por 24 horas (Figura 2).

3. Proceso de fijación y tinción. Una vez detectado crecimiento en las cajas de agar, se procedió a realizar la fijación y tinción de Gram de todas las muestras obtenidas, con el fin de determinar los tipos de bacterias (Figura 3). ${ }^{11}$

Se obtiene un campo estéril con el mechero de Bunsen y, con ayuda de la asa previamente esterilizada a la flama directa, se toma una prueba de las bacterias generadas en la caja Petri y se fija la muestra, después se coloca en el portaobjeto, dejando que se seque para posteriormente colocarles cristal violeta por 1 minuto; pasado este tiempo fueron enjuagadas con agua destilada, se coloca lugol por un minuto, se enjuagó con alcohol acetona, finalmente, se coloca safranina por 30 segundos y se enjuaga con agua destilada (Figura 4).

4. Visualización en el microscopio. Las muestras se vieron en el microscopio, de inicio con un enfoque al $40 \times$ y posterior a I 100× para su análisis (Figura 5).

Tabla 4: Presencia de bacterias por laboratorio.

\begin{tabular}{|c|c|c|c|c|}
\hline & \multirow[b]{2}{*}{ Laboratorio } & \multicolumn{2}{|c|}{ Bacteria } & \multirow[b]{2}{*}{ Total } \\
\hline & & Sí & No & \\
\hline \multirow[t]{2}{*}{1} & Recuento & 5 & 0 & 5 \\
\hline & $\%$ dentro de laboratorio & 100.0 & 0.0 & 100.0 \\
\hline \multirow[t]{2}{*}{2} & Recuento & 4 & 0 & 4 \\
\hline & $\%$ dentro de laboratorio & 100.0 & 0.0 & 100.0 \\
\hline \multirow[t]{2}{*}{3} & Recuento & 3 & 0 & 3 \\
\hline & $\%$ dentro de laboratorio & 100.0 & 0.0 & 100.0 \\
\hline \multirow[t]{2}{*}{4} & Recuento & 1 & 0 & 1 \\
\hline & $\%$ dentro de laboratorio & 100.0 & 0.0 & 100.0 \\
\hline \multirow[t]{2}{*}{5} & Recuento & 5 & 1 & 6 \\
\hline & $\%$ dentro de laboratorio & 83.3 & 16.7 & 100.0 \\
\hline \multirow[t]{2}{*}{6} & Recuento & 1 & 0 & 1 \\
\hline & $\%$ dentro de laboratorio & 100.0 & 0.0 & 100.0 \\
\hline \multirow[t]{2}{*}{ Total } & Recuento & 19 & 1 & 20 \\
\hline & $\%$ dentro de laboratorio & 95.0 & 5.0 & 100.0 \\
\hline
\end{tabular}




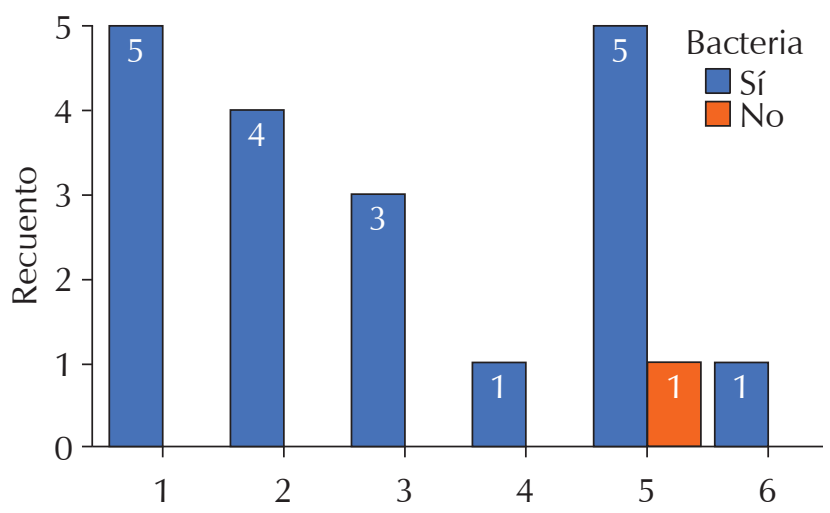

Figura 7: Presencia de bacterias por laboratorio.
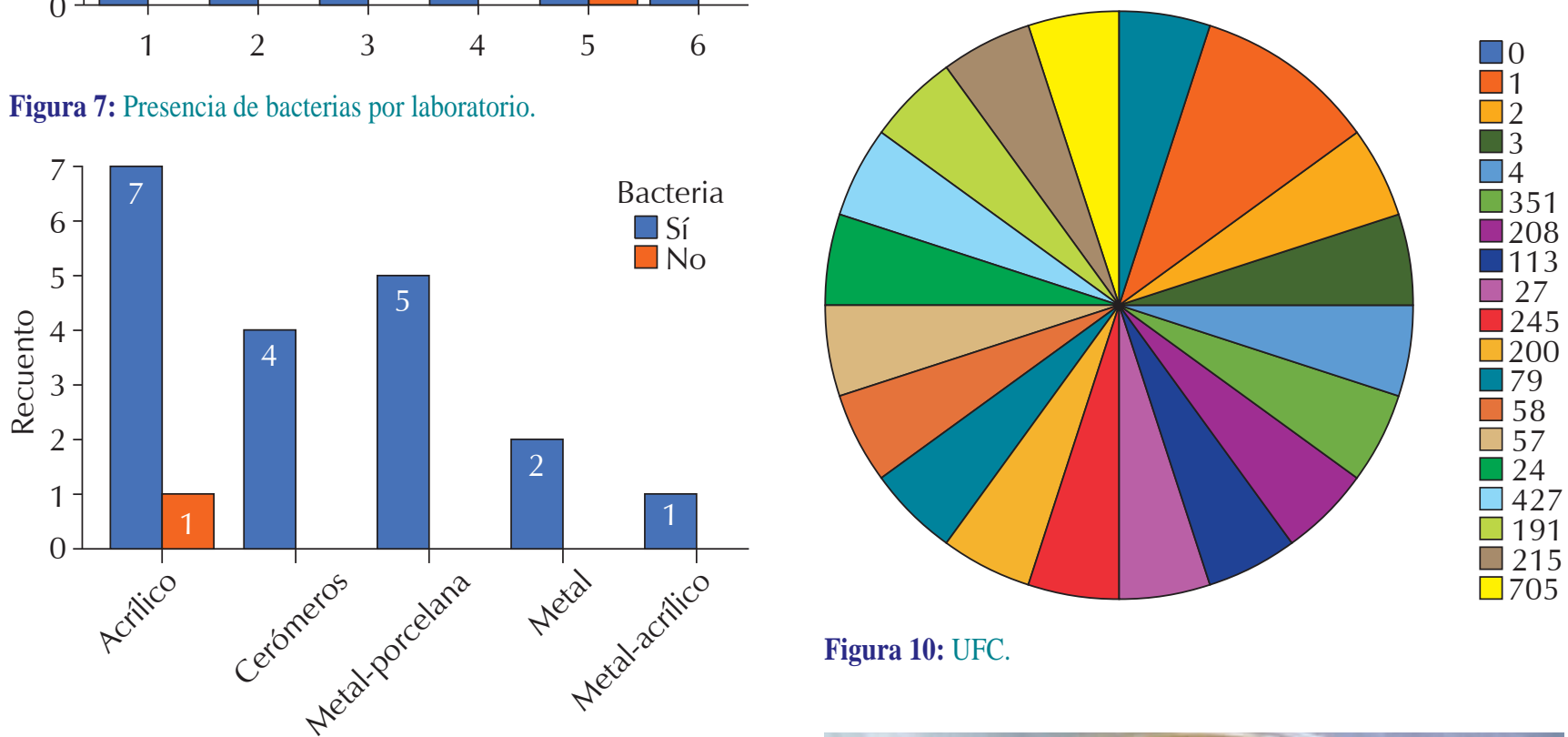

Figura 8: Presencia de bacterias por tipo de material.

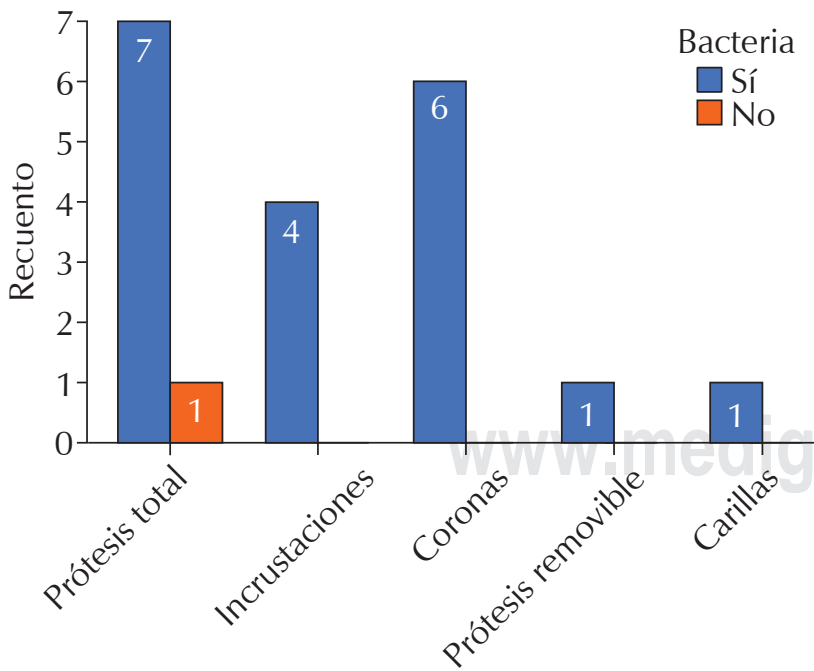

Figura 9: Presencia de bacterias por tipo de prótesis.

Figura 10: UFC.

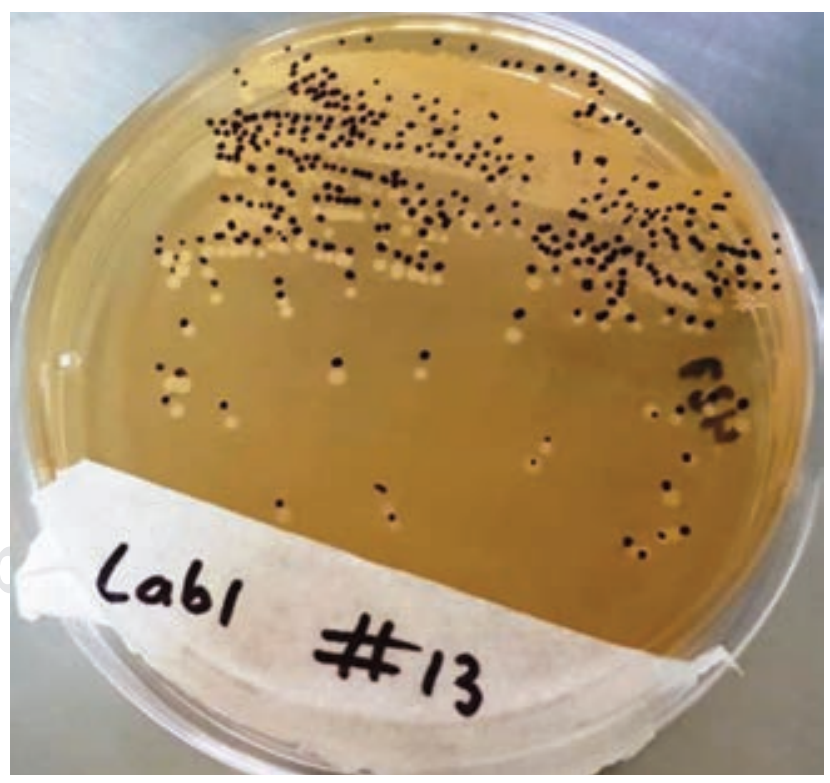

Figura 11: Muestra con UFC. 
Figura 12:

Bacterias detectadas.

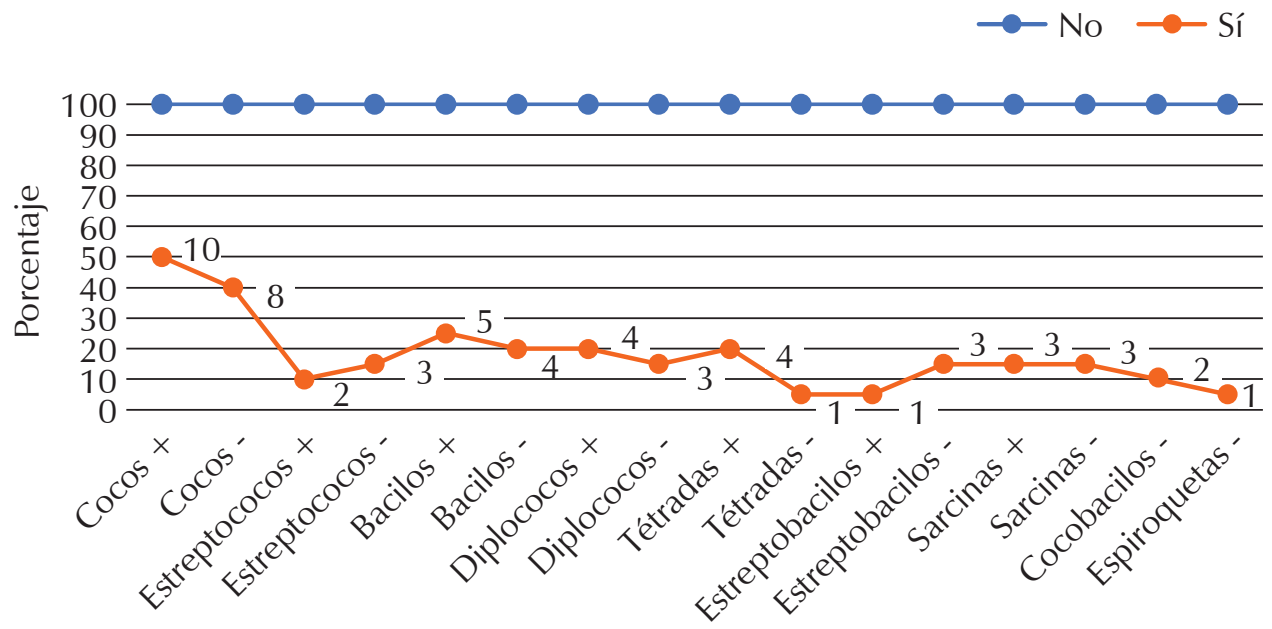

En cuanto al material de las prótesis dentales, pudimos darnos cuenta en la Figura 8 que el acrílico presentó mayor contaminación bacteriana. La Figura 9 indica que las prótesis que presentaron mayor presencia de UFC son las prótesis totales, seguidas de las coronas.

La Figura 10 nos indica que hubo prótesis muy contaminadas, ya que se encontraron muestras con 705 UFC; sin embargo, una de ellas no presentó crecimiento. En la Figura 11 podemos observar una muestra con UFC.

Dentro de las bacterias encontradas pudimos identificar que las de mayor prevalencia eran cocos Gram positivo y Gram negativo, seguido por los bacilos Gram positivo y Gram negativo; como podemos observar en la Figura 12. La Figura 13 muestra fotos de algunas bacterias identificadas en las prótesis.

En la prueba de ANOVA, en la distribución de medias de UFC por laboratorio, existió diferencia significativa en el número de UFC, obteniendo una $\mathrm{p}=0.715$ (Tabla 5 y Figura 14).
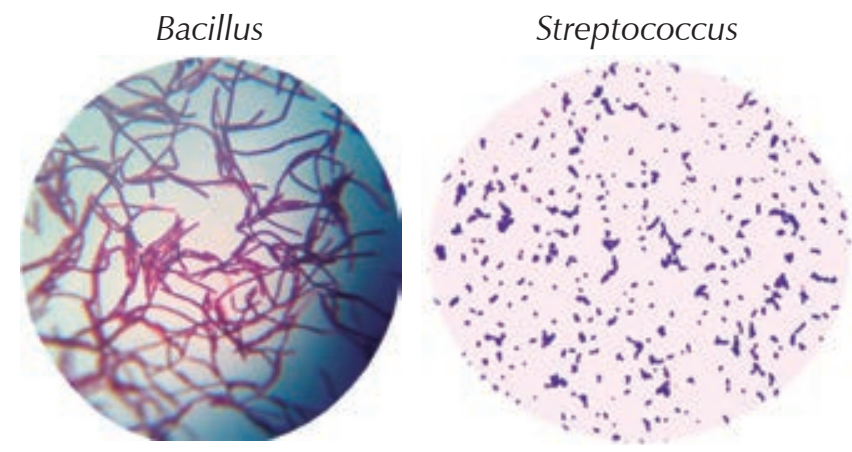

La prueba de ANOVA en la distribución de medias de bacterias por el tipo de prótesis dentales, indica que existió una diferencia significativa $p=0.859$ (Tabla 6 y Figura 15).

\section{DISCUSIÓN}

Un laboratorio dental es un área donde los técnicos dentales pueden infectarse principalmente por las impresiones sucias recibidas de las clínicas dentales. Por otro lado, la infección cruzada puede surgir entre el personal dental y los pacientes a partir de artículos contaminados enviados desde los laboratorios dentales a las clínicas dentales. ${ }^{5}$

La mayoría de las prótesis no se desinfectan antes de trabajar en ellas, lo que conlleva un riesgo de dispersión de patógenos por el laboratorio, con la consecuente posibilidad de contaminación cruzada de elementos pertenecientes a otros pacientes o de afectar a los propios
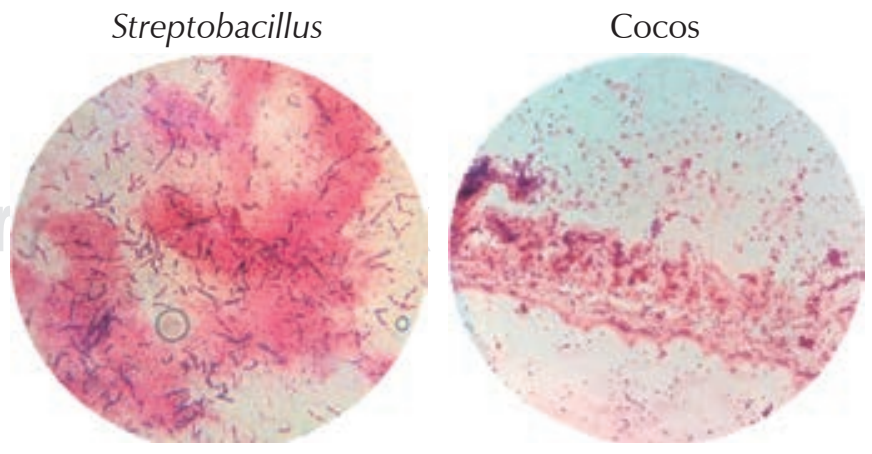

Figura 13: Fotos de bacterias identificadas. 


\section{Tabla 5: ANOVA distribución de medias UFC.}

\begin{tabular}{lcrccc} 
& $\begin{array}{c}\text { Suma de } \\
\text { cuadrados }\end{array}$ & gl & $\begin{array}{c}\text { Media } \\
\text { cuadrática }\end{array}$ & F & $\begin{array}{r}\text { Signifi- } \\
\text { cancia }\end{array}$ \\
\hline Entre grupos & 108.300 & 5 & 21.660 & 0.580 & 0.715 \\
$\begin{array}{l}\text { Dentro de grupos } \\
\text { Total }\end{array}$ & 522.500 & 14 & 37.321 & & \\
\hline
\end{tabular}

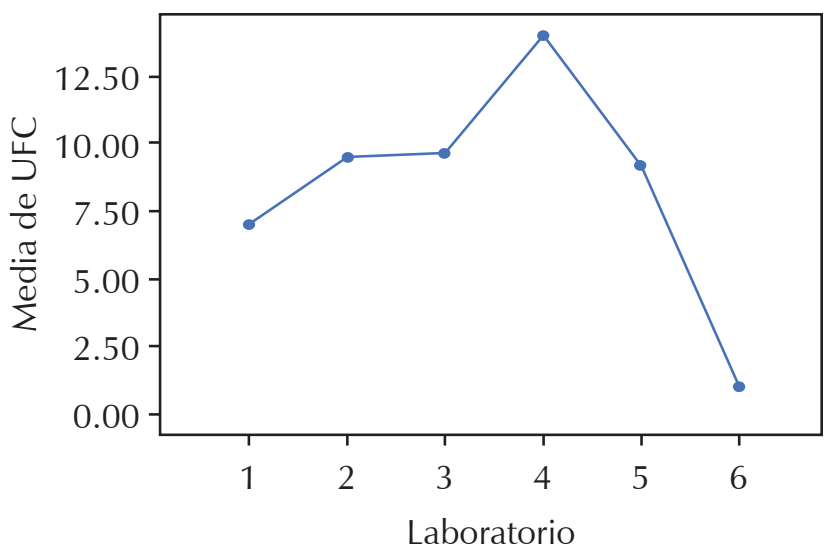

Figura 14: Distribución de medias UFC.

trabajadores del laboratorio y, posteriormente, al clínico durante su práctica. ${ }^{8}$

Se deben usar otras medidas de protección eficientes mientras se trabaja; estos métodos de protección reducirán el riesgo de contaminación cruzada, tanto para el técnico como para el clínico. ${ }^{12-14}$

Los resultados del presente estudio indicaron que la mayoría de los laboratorios dentales no cumplían con los procedimientos de control de infecciones, esto concuerda con el estudio realizado por Kugel. ${ }^{5}$

\section{CONCLUSIÓN}

Las prótesis entregadas por los laboratorios dentales no tienen la suficiente desinfección para poder colocarlas en la boca del paciente, esto nos da como conclusión que existe la presencia de bacterias en los aditamentos protésicos que son entregados por los diferentes laboratorios incluidos en esta investigación, ya que los laboratorios no emplean las medidas de desinfección y esterilización correctamente.

Las bacterias encontradas en los cultivos son Gram negativas y positivas, lo que determina que no sólo una clase de bacterias existieron en las prótesis y, como antes ya se había mencionado, sabemos que las bacterias que más dañan a nuestro organismo son las bacterias Gram positivas, pero no estamos exentos de que las Gram negativas también pueden causar enfermedades. Por eso es de gran importancia tener una buena desinfección de las prótesis dentales. Las bacterias encontradas morfológicamente de manera independiente a su división de Gram fueron cocos, bacilos, diplococos, estreptococos, tétradas, cocobacilos, sarcinas, estreptobacilos y espiroquetas, todas a excepción de una prótesis libre de metal tuvieron presencia de contaminación. También pudimos darnos cuenta de que existieron prótesis muy contaminadas con 705 UFC.

Para prevenir la infección cruzada entre laboratorio y el clínico, antes de proceder a su manipulación en el laboratorio y antes de ser llevados a la boca del paciente, se incluye la desinfección mediante la esterilización de todos los elementos potencialmente contaminados. ${ }^{15,16}$

\section{Tabla 6: ANOVA distribución de medias de bacterias.}

\begin{tabular}{lcrccc} 
& $\begin{array}{c}\text { Suma de } \\
\text { cuadrados }\end{array}$ & gl & $\begin{array}{c}\text { Media } \\
\text { cuadrática }\end{array}$ & F & $\begin{array}{c}\text { Signifi- } \\
\text { cancia }\end{array}$ \\
\hline Entre grupos & 0.075 & 4 & 0.019 & 0.321 & 0.859 \\
Dentro de grupos & 0.875 & 15 & 0.058 & & \\
Total & 0.950 & 19 & & & \\
\hline
\end{tabular}

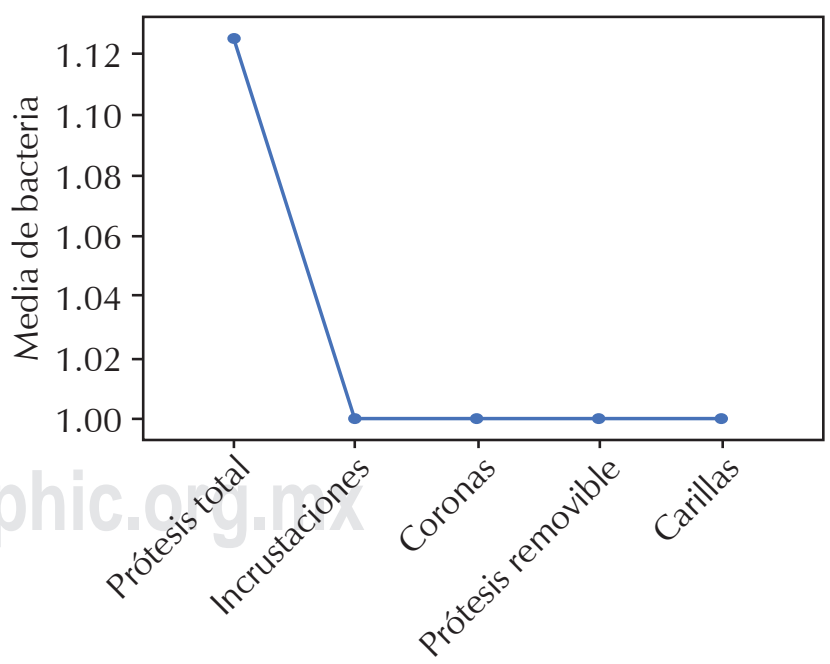

Tipo de prótesis

Figura 15: Distribución de medias de bacterias en prótesis. 
No obstante, es fundamental una comunicación adecuada entre la clínica y el laboratorio, pues repetidos procesos de desinfección pueden afectar a la precisión de los registros y comprometer la calidad de los tratamientos.

\section{REFERENCIAS}

1. González PZ, Tasende PA, Pereiro SM. Registro de pacientes portadores de prótesis en unidades de salud bucodental de Atención Primaria. Cad Aten Primaria. 2012; 18: 26-32.

2. Fuertes DEM. Laboratorio de prótesis dentales. España. Síntesis; 2017.

3. Sofou A, Larsen T, Fiehn NE, Owall B. Contamination level of alginate impressions arriving at a dental laboratory. Clin Oral Investig. 2002; 6 (3): 161-165.

4. Sedky NA, Hamid AA, Moazen RE. Study of awareness about infection control procedures in dental laboratories and prosthodontics clinics in al-qassim province, kingdom of Saudi Arabia. Egypt Dent J. 2013; 59 (3): 2703-2718.

5. Kugel G, Perry RD, Ferrari M, Lalicata P. Disinfection and communication practices: a survey of U.S. dental laboratories. J Am Dent Assoc. 2000; 131 (6): 786-792.

6. Diomedi A, Chacón E, Delpiano L, Hervé B, Jemenao MI, Medel Met al. Antisépticos y desinfectantes: apuntando al uso racional. Recomendaciones del Comité Consultivo de Infecciones Asociadas a la Atención de Salud, Sociedad Chilena de Infectología. Rev Chil Infectol. 2017; 34 (2): 156-174.

7. Troconis Ganimez JE. El control de infecciones en el laboratorio odontológico. Acta Odontol Venez. 2003; 41 (3): 258-265.

8. Vázquez Rodríguez I, Gómez Suárez R, Estany-Gestal A, Mora Bermúdez MJ, Varela-Centelles P, Santana Mora U. Control de la infección cruzada en los laboratorios de prótesis dental de Galicia. Anales Sis San Navarra. 2018; 41 (1): 75-82.

9. Ucar BA, Rojas de Méndez G, Ballester LA. Acción de agentes químicos en la eliminación de Candida albicans sobre prótesis dentales. Acta Odontol Venez. 2007; 45 (2): 172-177.

10. Hernández AM. NORMA Oficial Mexicana NOM-045-SSA2, Para la vigilancia epidemiológica, prevención y control de las infecciones nosocomiales, Estados Unidos Mexicano, Diario Oficial de la Federación 2005.

11. Rodríguez PA, Arenas R. Hans Christian Gram y su tinción. Dermatología Cosmética, Médica y Quirúrgica. 2018; 16 (2): 166167.

12. Al-Dwairi ZN. Infection control procedures in commercial dental laboratories in Jordan. J Dent Educ. 2007; 71 (9): 1223-1227.

13. Al-Kheraif AA, Mobarak FA. Infection control practice in private dental laboratories in Riyadh. Saudi Dental Journal. 2008; 20: 163-169.

14. Yamal RS y González AI. Causas de contaminación de prótesis fijas en elaboración, laboratorio dental CURN Cartagena, año 2013. Duazary. 2014; 11 (2): 98-104.

15. Barrancos MJ, Barrancos PJ. Operatoria dental. Integración clínica. 4a ed. Buenos Aires: Editorial Panamericana; 2006. p. 227.

16. Ozawa D, Yoshinori J. Fundamentos de prótesis total. México: Trillas; 2010. pp. 358-399.

Correspondencia:

Mónica Badillo Barba

E-mail: babm_1985@hotmail.com

Conflicto de intereses: Los autores declaran no tener ningún conflicto de intereses. 